Research report

\title{
David vs. Goliath: Serotonin modulates opponent perception between smaller and larger rivals
}

\author{
Andrew N. Bubak ${ }^{\mathrm{a}, *, 1}$, Nathaniel S. Rieger ${ }^{\mathrm{a}, 1}$, Michael J. Watt ${ }^{\mathrm{b}}$, Kenneth J. Renner ${ }^{\mathrm{b}}$, \\ John G. Swallow ${ }^{\mathrm{a}}$ \\ a University of Colorado-Denver, Denver, CO, United States \\ b Center for Brain and Behavior Research, University of South Dakota, Vermillion, SD, United States
}

\section{H I G H L I G H T S}

- 5-HT elevates aggression in smaller rivals, reminiscent of size-matched opponents.

- Larger opponents adjusted fighting strategy mid-contest to match increased aggression.

- Altered behavior suggests contextual flexibility based on opponent assessment.

\section{A R T I C L E I N F O}

\section{Article history:}

Received 15 May 2015

Received in revised form 3 July 2015

Accepted 7 July 2015

Available online 15 July 2015

\section{Keywords:}

Aggression

Serotonin

Game theory

Assessment

Fighting strategy

\begin{abstract}
A B S T R A C T
During agonistic encounters, the perception of a larger opponent through morphological signaling typically suppresses aggression in the smaller individual, preventing contest intensity escalation. However, non-morphological factors such as central serotonin (5-HT) activity can influence individual aggression, potentially altering contest intensity despite initial size discrepancies. When male stalk-eyed flies (Teleopsis dalmanni) fight, contest escalation is directly proportional to similarity in body size, with escalation being lower in size-mismatched contests. We have shown that both high-intensity aggression and the probability of winning are increased in males with pharmacologically elevated 5-HT relative to sizematched non-treated opponents. Here, we hypothesized that, in size-mismatched contests, increasing brain 5-HT in the smaller opponent could similarly increase aggression and counteract the low contest intensity normally driven by size discrepancy. Size-mismatched male pairs (greater than $5 \%$ difference in eyestalk length) engaged in a forced fight paradigm, with the smaller fly either untreated or with pharmacologically elevated 5-HT levels. The expression of high-intensity aggressive behaviors was significantly increased in smaller treated opponents, but the probability of winning was not altered. This suggests that while elevated serotonergic activity can increase aggression and intensity despite perception of a larger opponent, this is not sufficient to overcome size biases with respect to contest outcome. However, the fact that larger opponents continued to win against smaller treated flies was not simply a function of size. Instead, untreated larger males adjusted their fighting strategy to match the increased aggression of their smaller treated opponent, suggesting contextual flexibility in behavior based on individual opponent assessment.
\end{abstract}

(ㄷ) 2015 Elsevier B.V. All rights reserved.

\section{Introduction}

Aggressive contests are seen across many taxa and have important fitness implications for the individuals involved, resolving

\footnotetext{
* Corresponding author at: UCD Integrative Biology Department, Campus Box 171, POB 173364, Denver, CO 80217-3364, United States.

E-mail address: Andrew.Bubak@ucdenver.edu (A.N. Bubak).

1 Authors contributed equally.
}

conflicts among conspecifics over access to limited resources such as territory, food and mates [1]. Size discrepancy between competitors is an important factor in deciding conflict outcome [2]. A large discrepancy in body size, or ornament size in sexually selected species, often leads to quick contest resolution in favor of the larger competitor, because body size and ornament size can serve as reliable indices of resource holding potential [3]. Relative body size provides a ready means of opponent assessment and, in a variety of species, larger competitors often experience a greater likelihood of winning a direct encounter. Absolute body size is a dependable 
predictor of winning contests in crickets [4], crayfish [5], swimming crabs [6] and cichlid fish $[7,8]$. Similarly, ornament size reliably predicts contest outcome in many species. Examples of ornament size that have been positively associated with increased odds of winning contests include the head plume in male quail [9], casque and pink coloration size of Cape dwarf chameleons [10], the red spot of the American rubyspot [11] and comb size (along with body size) in the red jungle fowl [12].

Opponent assessment, aggression and conflict resolution are modulated by central monoaminergic activity $[8,13]$ altering of which may be sufficient to overcome initial size-biased disparities. In some arthropods, increased activity of the monoamine serotonin (5-HT) is associated with either greater expression of high-intensity aggression or decreased likelihood of retreating from an agonistic encounter, depending on the species [5,14-18]. This finding is supported by studies in which individual aggressive behavior is heightened by increasing 5-HT levels through either pharmacological or genetic manipulations [5,15,19-21]. While the role of 5-HT in arthropods in aggressive expression and contest outcome between size-matched opponents is relatively well studied and clear, with some conflicting results, the effects of 5-HT manipulation on opponent assessment and contest outcome in size-mismatched contests is equivocal and understudied. For example, Huber et al. [5] found that increased 5-HT in one crayfish species decreased the willingness of smaller subordinate animals to retreat but did not increase the chance of winning a contest. In contrast, Momohara et al. [14] reported that elevating 5-HT in another species of crayfish increased not only levels of aggression but also likelihood of winning. However, both studies suggest that 5-HT is important for modulating aggression, including decisions regarding initiation, escalation or retreat, and can promote smaller individuals to overcome initial opponent assessments based on body size.

We have been developing the sexually dimorphic stalk-eyed fly, Teleopsis dalmanni, as a model for investigating mechanisms underlying aggression, escalation, and conflict resolution, because males use their elongated eyestalks as communicative signals in two different aggressive contexts [22]; male flies defend both diurnal feeding sites $[23,24]$ and nocturnal roosting sites that allow mating access to females [25-27]. Larger males with broader eye spans (i.e., longer eyestalks) typically win contests in both situations $[28,29]$. However, smaller males do win a small percentage of these interactions [24,30]. Agonistic encounters between males follow a stereotyped escalated progression from lower to higher intensity actions consistent with sequential assessment (but see [31]) that are terminated when one of the rivals capitulates and retreats [32], typically without injury.

The exact mechanisms underlying opponent assessment in stalk-eyed flies that eventually lead to conflict resolution are not well understood. However, we have recently developed methods to quantify and to pharmacologically manipulate 5-HT in the brains of individual stalk-eyed flies [33], allowing us to investigate its proximate role in regulating and constraining aggression. In previous studies, we found that stalk-eyed flies which had higher brain 5 -HT relative to an opponent showed increases in the expression of aggressive behaviors, decreases in the number of retreats and that higher 5-HT resulted in a markedly increased likelihood of winning against a size-matched competitor [34]. These results indicate an important role of 5-HT in both conflict escalation and conflict resolution in this species. In this study, we determined whether increasing brain 5-HT could overcome the escalation pattern and outcome of an aggressive contest normally predicted by a size discrepancy. We hypothesized that pharmacologically increasing 5-HT in smaller males, "David", would increase both aggressive behaviors and contest escalation while decreasing willingness to retreat despite the initial assessment of a larger untreated opponent, "Goliath". Concurrently, we observed whether the larger opponent's behavior changed as a result of the pharmacologically-enhanced aggression of smaller flies. Increased aggressive responses by larger males toward treated smaller males would indicate that agonistic reactions can be modulated according to the perceived level of opponent aggression, surpassing assessment of a supposedly weaker competitor based initially on body size alone. Thus, we predicted that if larger flies were assessing their opponents, in part by the opponent's level of aggression, then they would react with escalated aggression in a manner more reminiscent of size-matched contests.

\section{Methods}

\subsection{Subjects}

Male stalk-eyed flies, Teleopsis dalmanni, used in this experiment were all descendants of pupae collected by Dr. Gerald Wilkinson (University of Maryland-College Park) from Gomback Field Station near Kuala Lumpur, Malaysia in 2012. Flies in this study were housed communally $(\sim 100)$ in clear plastic cages $(45 \times 22 \times 19 \mathrm{~cm})$ with access to food and water ad libitum on a $12 \mathrm{~h}$ light/dark cycle at constant temperature $\left(25^{\circ} \mathrm{C}\right)$ and humidity ( 70\%) [35]. Cages included hanging string to mimic rootlets found in the natural habitat, which promotes natural mating and competitive behavior among males. Study males were between three weeks and 2 months post-eclosion. Males were anesthetized with $\mathrm{CO}_{2}$, positioned on their thoracic spines, and eye span was measured to the nearest $0.01 \mathrm{~mm}$ using scion image [36]. Eye span differences in this species serve as a reliable index for body size difference $[35,37]$. Therefore, opposing pairs of size-mismatched males were established based on a minimum of $5 \%$ difference in eye span. The males were assigned to 3 treatment groups, comprised of untreated smaller opponents $(n=20)$, pharmacologically treated smaller opponents $(n=20)$, and untreated larger opponents (facing either a treated or untreated smaller opponent, $n=20$ per group). Respective groups were then transferred to smaller cages $(14 \times 14 \times 14 \mathrm{~cm})$ housing between 2 and 6 flies. Food and water were provided ad libitum.

\subsection{Pharmacological manipulation}

Sterilized and pureed sweet corn kernels were prepared according to [33]. Both untreated and treated food media included $1 \mathrm{~mL} / 100 \mathrm{~mL}$ methylparaben as a mold inhibitor, $25 \mathrm{mg}$ of ascorbic acid to act as a stabilizer, and food coloring to ensure uniform mixing. Treated food media also included $3 \mathrm{~g} / 100 \mathrm{~mL}$ of 5-hydroxyL-tryptophan (Sigma-Aldrich, St Louis, MO) [33]. Flies were allowed access to the treated corn ad libitum for 4 days prior to trials, which reliably produces a minimum 8 -fold increase of brain 5-HT content relative to non-treated flies [33].

\subsection{Forced-fight paradigm}

After the 4-day feeding period, size mismatched fighting pairs were placed in an arena $(11 \times 6.5 \times 5 \mathrm{~cm}$ rectangle containing a removable glass ceiling and glass wall) containing moist filter paper as a floor and a removable central cardboard barrier that separated the individuals, but no food was provided [30,32]. Twelve hours after placement in the arena, the cardboard divider was removed and a small piece of pureed corn (approximately $5 \mathrm{~mm}$ in diameter) was introduced to initiate the contest [33]. This 12-h starvation period promotes willingness to engage in aggressive behaviors over a food resource [30,32]. The interactions were then recorded for 10 min using a digital video recorder for later scoring of behavior. 


\subsection{Dissection and sample preparation}

Immediately following the behavioral contest, flies were aspirated out of the arena and anesthetized with $\mathrm{CO}_{2}$. The heads were immediately removed under a microscope at $40 \times$ magnification using micro-scissors. Eye stalks and mouthparts were both removed, as these contain residual food, tissue, and pigments that can interfere with analysis of brain tissue. Micro-tweezers were inserted into the oral cavity to split open the exoskeleton and expose the brain. The exposed neural tissue and surrounding exoskeleton were then placed into $60 \mu \mathrm{L}$ of acetate buffer containing the internal standard $\alpha$-methyl-dopamine and stored at $-80^{\circ} \mathrm{C}$. The dissection process took less than 1 min per fly.

\subsection{Data acquisition}

5-Hydroxytryptophan (5-HTP) and 5-HT were measured in single whole brain samples using high performance liquid chromatography with electrochemical detection using a method adapted from Bubak et al. [33]. Frozen samples were thawed and then centrifuged at $17,000 \mathrm{rpm}$ at $4{ }^{\circ} \mathrm{C}$. The supernatant was removed and $45 \mu \mathrm{L}$ of the sample was injected into the chromatographic system. Amines were separated using a $\mathrm{C}_{18} 4 \mu \mathrm{m}$ NOVA-PAK radical compression column (Waters Associates Inc., Milford, MA) and detected using an LC 4 potentiostat and a glassy carbon electrode (Bioanalytical Systems, West Lafayette, IN). The sensitivity was set at $1 \mathrm{nA} / \mathrm{V}$ with an applied potential of $+0.9 \mathrm{~V}$ vs. an $\mathrm{Ag} / \mathrm{AgCl}$ reference electrode. The mobile phase was made by dissolving $8.6 \mathrm{~g}$ sodium acetate, $250 \mathrm{mg}$ EDTA, $11 \mathrm{~g}$ citric acid, $130 \mathrm{mg}$ octylsulfonic acid in water, and adding $160 \mathrm{~mL}$ of methanol to a final volume of $1 \mathrm{~L}$ distilled water. The $\mathrm{pH}$ was adjusted to 4.1. All chemicals were obtained from Sigma-Aldridge (St. Louis, MO). The remaining tissue pellet was solubilized in $60 \mu \mathrm{L}$ of $0.4 \mathrm{M} \mathrm{NaOH}$ and analyzed for protein using the Bradford method [38]. Amine concentrations were determined using a CSW32 data program set in internal standard mode using peak height values relative to standards. The resulting concentrations were divided by $\mu$ g protein in the sample yielding pg amine/ $\mu \mathrm{g}$ protein and corrected for injection vs. preparation volume.

\subsection{Behavioral analysis}

For each individual, the number and duration of separate interactions (beginning with lining up eyestalks to conflict resolution) occurring within the $10 \mathrm{~min}$ forced fight were measured. Specific behaviors of each opponent were also measured, based on an ethogram adapted from Egge et al. [32]. The behaviors included within the ethogram were mutually exclusive so that only one behavior during an aggressive interaction could occur at any given time. Any behaviors occurring outside an aggressive interaction were not scored. An aggressive interaction began with the approach of a fly toward its opponent or by the mutual lining up of eye stalks between opponents. The behaviors scored for each opponent fall into three categories; low-intensity behaviors, high-intensity behaviors, and conflict resolution behaviors. Low-intensity behaviors consist of aggressive behaviors that do not include physical contact with an opponent, such as contest initiation (approaching an opponent that ultimately results in an aggressive confrontation), flexing, and rearing. Only one of the opponents was awarded a score for contest initiation at the beginning of each interaction, if both flies appeared to approach their opponent and line up simultaneously no initiation score was awarded. High-intensity behaviors are denoted by physical contact between opponents, including swiping motions with the forelegs toward the opponent, tussling in which the competitors interlock forelegs, and jump attacking where a competitor jumps or climbs onto the back of its
Table 1

Whole brain 5-HT concentrations in 5-HTP pretreated Davids, untreated Davids, and Goliaths. (Values presented as mean \pm SEM)

\begin{tabular}{lc}
\hline & 5-HT $(\mathrm{pg} / \mu \mathrm{g}$ protein $)$ \\
\hline Smaller untreated & $15 \pm 0.5$ \\
Smaller treated & $180.8 \pm 35.1$ \\
Larger (untreated opponent) & $17.2 \pm 2$ \\
Larger (treated opponent) & $19.8 \pm 1.2$ \\
\hline
\end{tabular}

opponent. Conflict resolution was marked by behaviors which led to the aggressive interaction being halted for a minimum of $3 \mathrm{~s}$. Behaviors that could cause this resolution included slowly walking away from an opponent, retreating (swiftly moving in opposite direction from opponent) from or pursuing an opponent, or becoming unaligned from the opponent. Behaviors were scored using the behavioral software Jwatcher [39]. Along with these behaviors, duration of individual interactions (beginning with lining up eyestalks to conflict resolution) was also measured. Fights were scored by experimenters blind to treatment, with each fly's behavior measured separately. As fights consist of multiple aggressive interactions, the contest outcome was determined by the number of retreats such that the fly engaging in more retreat behaviors was designated to be the loser and its opponent the winner [32].

\subsection{Statistical analysis}

A one-way ANOVA with a Tukey's multiple comparisons test was used to test for differences in 5-HT concentrations between all groups. Separate unpaired Student $t$-tests were used to test for differences in means for number of interactions, initiations, highintensity behaviors, or escalations between treated and untreated smaller opponents, or between larger competitors facing treated vs. untreated opponents. The likelihood of being the first to either escalate or initiate an interaction was determined within each treatment group using separate Fisher's exact tests employing a two-tailed contingency table. The probability of either treated or untreated smaller opponents winning the entire $10 \mathrm{~min}$ forced fight was also determined using a Fisher's exact test. All statistical tests were conducted using Prism 6 (GraphPad Software) with a set 0.05 alpha level.

\section{Results}

\subsection{Pharmacological manipulation of 5-HT}

Pretreatment with 5-HTP resulted in a significant elevation of brain 5-HT in treated smaller flies when compared to all other groups (one-way ANOVA, $F(3,76)=21.61, p<0.001$; Table 1 ). Treated competitors had an approximately 12 -fold increase compared to untreated competitors $(180.8 \pm 35.1$ vs. $15 \pm 0.5 \mathrm{pg} / \mu \mathrm{g}$ protein; Table 1). The 5-HT concentrations in larger opponents of both treated and untreated smaller rivals were not significantly different ( $19.8 \pm 1.2$ vs. $17.2 \pm 2 \mathrm{pg} / \mu \mathrm{g}$ protein; Table 1$)$. In previous studies, using the same dose of 5-HTP, the increase in 5-HT was approximately two-fold $[33,34]$. We have no explanation for this discrepancy.

\subsection{Aggressive behavior and fight outcome in treated flies}

Smaller treated males engaged in significantly more aggressive interactions during the $10 \mathrm{~min}$ forced fight with their larger opponent compared to dyads containing untreated smaller opponents (mean \pm SEM; $4.95 \pm 0.6$ vs. $3.4 \pm 0.39$, respectively; Student's $t$-test, df (38), $p=0.0361$; Fig. 1A). Furthermore, smaller treated flies won or tied significantly more of these aggressive interac- 
A



B

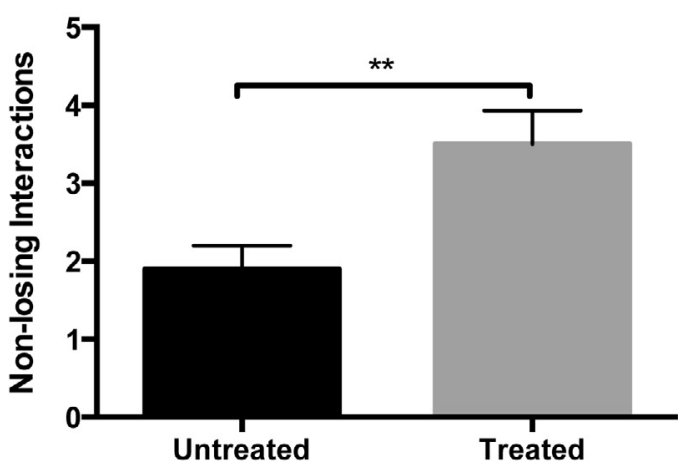

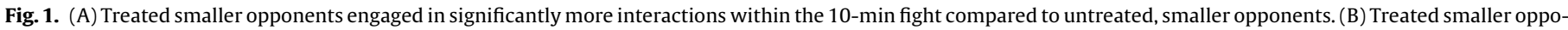

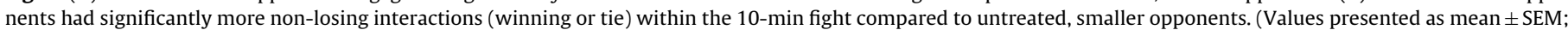
Student's $t$-test)

A

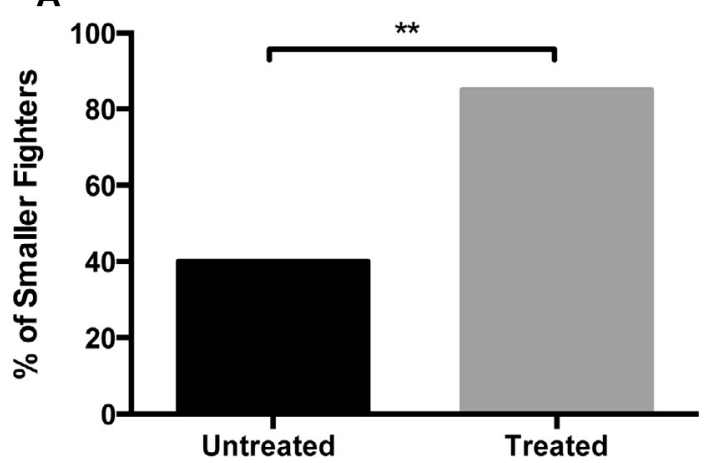

B

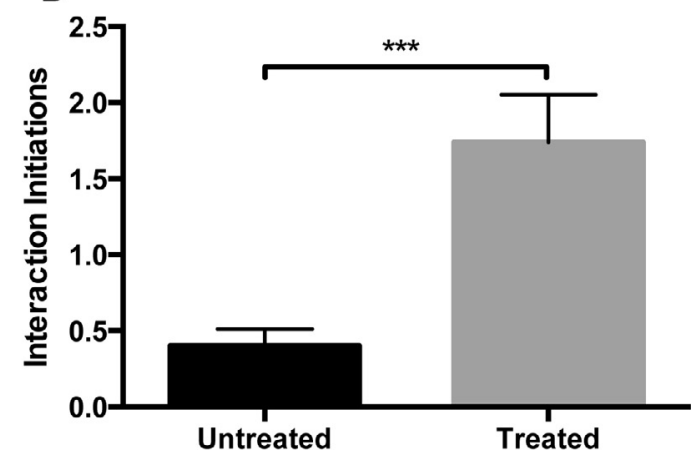




average compared to untreated smaller opponents (values presented as mean \pm SEM; Student's $t$-test).

tions compared to smaller untreated flies (mean \pm SEM; $3.5 \pm 0.43$ vs. $1.9 \pm 0.3$, respectively; Student's $t$-test, df (38), $p=0.0041$; Fig. 1B). The mean duration of interactions within a fight involving treated and untreated opponents remained essentially unchanged (13.19 $\mathrm{s} \pm 1.14$ vs. $13.03 \mathrm{~s} \pm 2.13$; Student's $t$-test, $p=0.92$ ).

Treated smaller opponents were also more likely than untreated smaller opponents to initiate aggression during the $10 \mathrm{~min}$ forced fight, with 18 out of 20 treated flies initiating at least one aggressive interaction. In contrast, only 7 of the 20 untreated smaller flies initiated aggressive behaviors (Fisher's exact test $p=0.0079$, Fig. 2A). Furthermore, treated males performed approximately four times as many initiations in a fight compared to untreated individuals (mean $\pm S E M$; $1.75 \pm 0.32$ vs. $0.4 \pm 0.11$; Student's $t$-test, df (38), $p=0.0003$; Fig. 2B). Treated, smaller opponents also produced twice as many high-intensity behaviors (physical contact) during their interactions compared to untreated, smaller opponents (mean $\pm S E M ; 2.45 \pm 0.44$ vs. $1.2 \pm 0.33$; Student's $t$-test, df (38), $p=0.0282$; Fig. 3). However, smaller, treated flies did not show an increased likelihood of escalating an encounter to high-intensity levels, judged by being the first to engage in swiping, tussling, or jumping (mean \pm SEM; $0.75 \pm 0.22$ vs. $0.45 \pm 0.18$; Student's $t$ test, $\mathrm{df}(38), p=0.31$ ). Out of 20 treated, smaller flies, 8 escalated a contest compared to 5 untreated smaller flies (Fisher's exact test $p=0.5$ ). Smaller treated competitors, despite having more successful interactions within the $10 \mathrm{~min}$ contest, also did not show a greater probability of winning the entire 10 min forced fight when compared to untreated competitors, winning 4 of 20 fights with 7 draws while their untreated counterparts won 3 of 20 fights with 6 draws (Fisher's Exact Test, $p=0.67$ ).

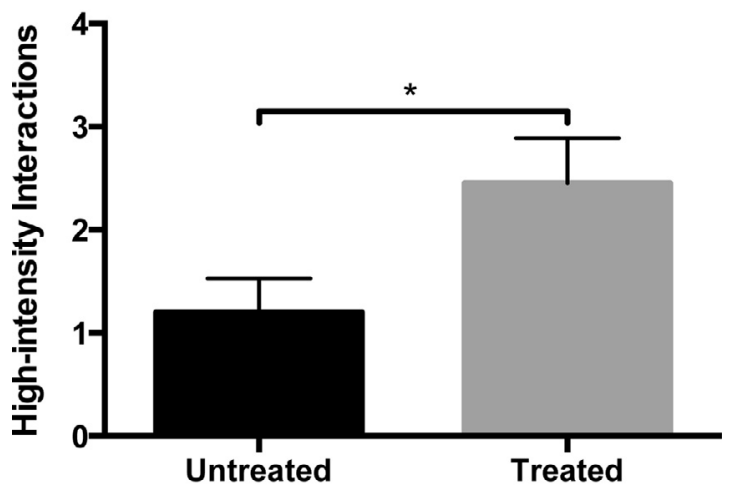

Fig. 3. Treated smaller opponents engaged in significantly more high-intensity interactions compared to untreated smaller opponents (values presented as mean \pm SEM; Student's $t$-test).

\subsection{Aggressive responses of larger opponents toward treated rivals}

Larger males facing treated smaller opponents performed a greater number of high-intensity behaviors during their interactions than those facing untreated, smaller opponents (mean $\pm S E M$; $5.5 \pm 1.1$ vs. $1.94 \pm 0.84$; Student's $t$-test, df (36), $p=0.0137$; Fig. $4 \mathrm{~A}$ ). The mean number of escalations for larger flies facing treated opponents was also significantly higher than larger flies facing untreated opponents (mean \pm SEM; $1.7 \pm 0.33$ vs. $0.75 \pm 0.32$; Student's $t$-test df (38), $p=0.045$; Fig. 4B). Likewise, individual larger competi- 
A

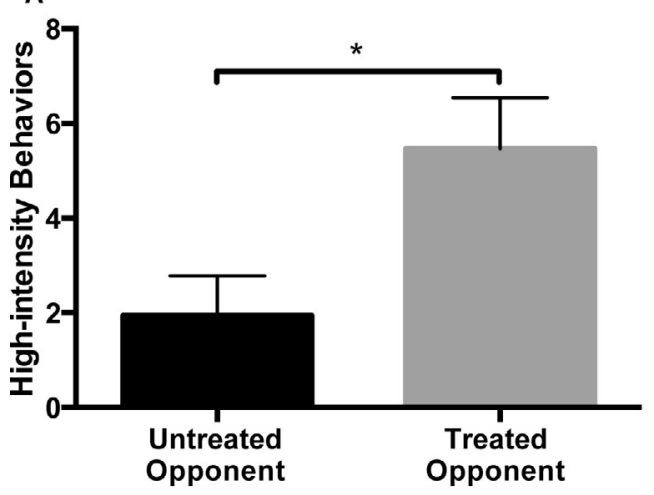

B

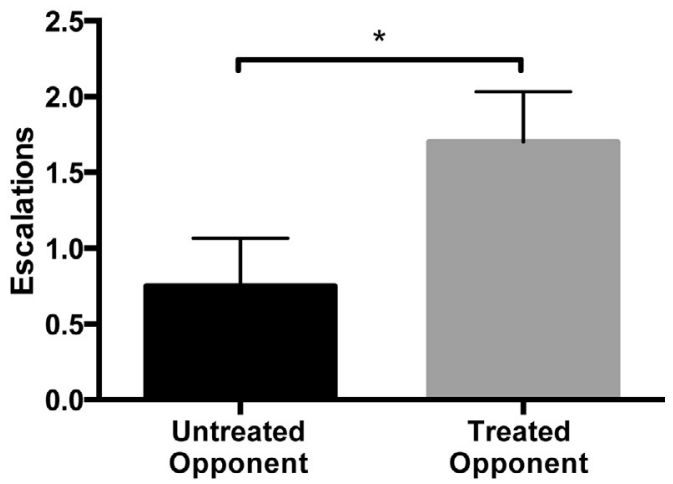

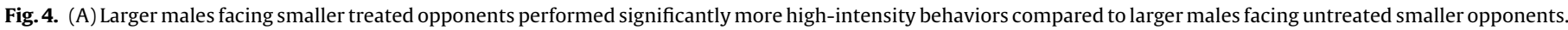

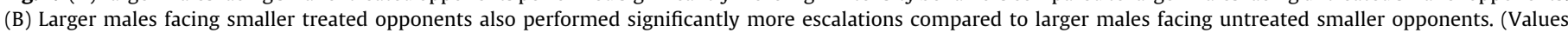
presented as mean \pm SEM; Student's $t$-test).

\section{Escalated Interactions}

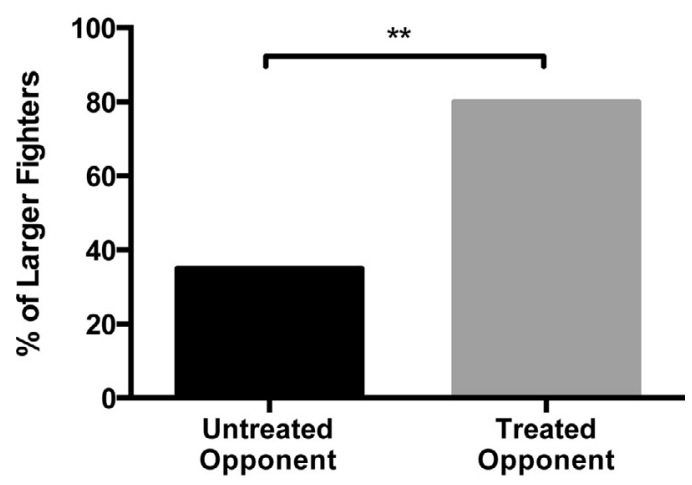

Fig. 5. A significantly higher percentage of larger males that fought treated smaller opponents escalated an interaction during the 10-min fight compared to larger males that fought untreated smaller opponents (Two-tailed contingency table, Fisher's exact test).

tors facing treated opponents were more likely to escalate fights, defined as being the first to perform a high intensity behavior (make physical contact) such as swiping, tussling or jump attack in an already ongoing aggressive contest, than larger competitors facing an untreated counterpart (16 vs. 7 individuals, respectively; Fisher's exact test, $p=0.0095$, Fig. 5). However, the number of aggressive interactions initiated by larger males toward either treated or untreated smaller males during the 10-min fight did not differ (mean \pm SEM; $2.65 \pm 0.35$ vs. $2.05 \pm 0.27$; Student's $t$-test, df (38), $p=0.18$ ). The likelihood of larger individuals initiating at least one interaction was also not significantly different when facing either a treated or untreated opponent ( 20 vs. 18 individuals, respectively; Fisher's exact test, $p=0.49$ ). Thus, larger flies needed to be in an already progressing aggressive interaction before they altered their behavior by escalating to higher intensities; an effect that is amplified when facing treated opponents.

\section{Discussion}

In this study, we examined the effects of 5-HT manipulation on smaller competitors to determine whether elevated 5-HT levels would be able to overcome the normal size biases of opponent assessment and contest escalation. Previous studies have shown that larger male stalk-eyed flies win more than $75 \%$ of contests in which the combatants differed by more than $5 \%$ in eye span $[24,30]$. Additionally, in a size-matched contest, males with 5-HT pharmacologically elevated by roughly 2 -fold won $85 \%$ of the time against control males [33] and displayed greater levels of high-intensity behaviors and fewer retreat behaviors [34]. Following the procedures developed by Bubak et al. [33], we manipulated brain 5-HT levels of smaller competitors by oral administration of its metabolic precursor, 5 -HTP, resulting in a nearly 12 -fold 5 -HT increase in the treated smaller flies relative to all other groups. Despite the large increase in 5-HT, pre-treatment with 5-HTP did not affect overall contest outcomes; that is, the treatment did not result in the smaller competitor, "David", slaying the larger "Goliath". However, it did significantly alter the progression of the contest and the types of aggressive behaviors displayed by both the larger and smaller opponents, consistent with our predictions.

Treated smaller flies showed an increased willingness to engage and persist in aggressive contests, corroborating the findings of Bubak et al. [34] which showed that flies with elevated 5-HT were less likely to retreat in contests with size-matched opponents. Consistent with our results, Huber et al. [5] also demonstrated that subordinate crayfish treated with 5-HT were less willing to retreat, but that overall contest outcome remained unchanged, with subordinate competitors still more likely to lose. In our study, increasing brain 5-HT also increased the likelihood that smaller flies would engage in aggressive contests, promoting both the initiation and number of aggressive interactions. This may indicate that heightened 5-HT either increased motivation to engage in an aggressive contest or artificially enhanced self-perception of resource holding potential (i.e., fighting ability). Finally, treated males engaged in more high-intensity behaviors (swiping, tussling, and jump attacks) than untreated males. The increased high-intensity interactions and behaviors in treated flies suggests that 5-HT plays an important role in the decision to not only remain in a contest but also to persist in expressing high levels of aggression despite discrepancies in body size.

Interestingly, despite the increased number of high-intensity behaviors exhibited in contests including treated smaller flies, contest duration did not change, indicating that the escalation and continuation of high-intensity encounters was not simply a byproduct of the contest lasting longer. Together, these behavioral differences between treated and untreated flies indicate that 5-HT may either be involved in rival assessment or in controlling the willingness to engage in risky behaviors, rather than being absolutely necessary for the expression of aggression. Although it was initially reported that neural 5-HT had a limited or absent role in insect aggression (e.g., crickets and Drosophila; $[40,41])$, more recent studies suggest, at least for some species, the contrary [reviewed in [42]]. For example, decreasing 5-HT activity in male Drosophila reduces fight escalation but does not abolish aggression [15,21] while increasing 5-HT increases aggression [15]. However, the pre- 
cise physiological mechanism by which 5-HT modulates aggression is still unknown. It is likely that particular 5-HT receptor subtypes contribute to the expression and inhibition of distinct aggressive behaviors as seen in Drosophila [16]. This mechanism could be extended further by the possibility of these receptors controlling the release of other neurochemicals known to increase aggression in insects such as octopamine [40,43-47]. The underlying proximate mechanisms by which 5-HT modulates aggression as well as the correlation with other biochemical systems should be the focus of future studies.

Intriguingly, 5-HTP treated, smaller flies were not the only competitors to show a change in aggressive behavior. The larger flies competing against smaller, treated males performed significantly more high-intensity behaviors than their counterparts facing untreated, smaller opponents (Fig. 4A), and also engaged in a higher number of interactions that escalated in intensity. However, it was only the larger competitor, and not their treated opponents, that showed greater likelihood of being the first to escalate a contest by expressing a high-intensity behavior. The number of contests initiated by larger males remained the same regardless of whether the opponent was treated. This suggests that the larger flies are driving the escalation of these aggressive contests in response to the greater frequency of aggressive behaviors displayed by the smaller opponents with elevated 5-HT levels. Since treated flies but not their opponents initiated more aggressive interactions, the heightened aggressive reaction by the larger flies suggests that the smaller opponents may have evoked an overt aggressive response from the larger opponent, which normally would have won the fight simply by posturing. In essence, smaller, treated flies appear to be "poking a sleeping giant" and forcing an escalation response from their larger opponent despite the potential negative consequences.

Our results stand in contrast to Huber et al. [5] who found that the main effect of 5-HT elevation in subordinate crayfish was to increase the duration of contests between smaller and larger opponents, which appeared to be driven by the smaller opponent's unwillingness to retreat and not by escalation of fighting patterns by either the dominant or subordinate opponent specifically. In this study, we did see increased initiations of aggressive encounters and increased interactions by treated flies, alluding to a willingness to fight, despite the duration of these contests not being increased. Similarly, Momohara et al. [14] found that smaller crayfish (of a different species from that examined by Huber et al. [5]) treated with 5-HT showed an increase in aggressive behaviors toward larger opponents, but not in contest duration. However, in contrast to our study, Momohara et al. [14] demonstrated that 5-HT elevations increased the likelihood of winning contests against larger opponents. A possible explanation of the discrepancy between our study and that of Momohara et al. [14] is that the larger opponent's perception of their treated opponent was altered, leading to the increase in escalation behaviors and resulting in a more costly fight that would favor a larger competitor. Thus, our study indicates that treatment of the smaller rival results in the alteration of behaviors of both opponents, providing clues to the assessment strategies used by stalk-eyed flies and the degree of behavioral information they perceive during a confrontation.

Overall, we found that increasing brain 5-HT in smaller opponents led not only to an increased willingness to engage in aggressive encounters but also an increased production of highintensity behaviors, consistent with previous studies [5,14,17,34]. Furthermore, while the smaller treated flies increased aggression and were more likely to initiate aggressive contests and engage in risky high-intensity behaviors, it was actually their larger opponents that showed a higher likelihood of being the first to express a high intensity behavior. This implies that aggressive behavior is not fixed in these individuals, but can be modified in a contextuallyappropriate manner beyond initial morphological perception by incorporating assessments of opponent behavior as the interaction proceeds.

\section{Acknowledgements}

We would like to thank Dr. Jaime Grace, Harper Jocque and Tangaline Romero for thoughtful comments on this manuscript as well as the anonymous reviewers for their helpful critiques. This work was funded by NSF grants IOS 1256898 (JGS), andIOS 1257679 (MJW).

\section{References}

[1] J. Archer, The Behavioural Biology of Aggression, Cambridge University Press, Cambridge, 1988.

[2] F.A. Huntingford, A.K. Turner, Animal Conflict, Chapman and Hall, London, 1987.

[3] G.A. Parker, Assessment strategy and the evolution of fighting behavior, J. Theor. Biol. 47 (1974) 223-243.

[4] K.A. Dixon, W.H. Cade, Some factors influencing male-male aggression in the field cricket Gryllis integer (time of day, age, weight and sexual maturity), Anim. Behav. 34 (1986) 340-346

[5] R. Huber, K. Smith, A. Delago, K. Isaksson, E.A. Kravitz, Serotonin and aggressive motivation in crustaceans: altering the decision to retreat, Proc. Natl. Acad. Sci. U. S. A. 94 (1997) 5939-5942.

[6] C.W. Glass, F.A. Huntingford, Initiation and resolution of fights between swimming crabs (Liocarcinus depurator), Ethology 77 (2010) 237-249.

[7] M. Enquist, O. Leimar, T. Ljungberg, N. Segerdahl, A test of the sequential assessment game: fighting in the cichlid fish Nannacara anomala, Anim. Behav. 40 (1990) 1-14

[8] G.F. Turner, The fighting tactics of male mouthbrooding cichlids: the effects of size and residency, Anim. Behav. 47 (1994) 655-662.

[9] J.C. Hagelin, The kinds of traits involved in male-male competition: a comparison of plumage, behavior, and body size in quail, Behav. Ecol. 13 (2001) 32-41

[10] D.M. Stuart-Fox, D. Firth, A. Moussalli, M.J. Whiting, Multiple signals in chameleon contests: designing and analyzing contests as a tournament Anim. Behav. 71 (2006) 1263-1271.

[11] J. Contreras-Garduno, B.A. Buzzatto, M.A. Serrano-Meneses, K. NajerA-Cordero, A. Cordoba-Aguilar, The size of the red wing spot of the American rubyspot as a heightened condition-dependent ornament, Behav. Ecol. 19 (2008) 724-732.

[12] J.D. Ligon, R. Thornhill, M. Zuk, K. Johnson, Male-male competition, ornamentation and the role of testosterone in sexual selection in the red jungle foul, Anim. Behav. 40 (1990) 367-373.

[13] J.J. Schwarzer, L.A. Ricci, R.H. Melloni Jr., Prior fighting experience increases aggression in Syrian hamsters: implications for a role of dopamine in the winner effect, Aggress. Behav. 39 (2013) 290-300.

[14] Y. Momohara, A. Kanai, T. Nagayama, Aminergic control of social status in crayfish agonistic encounters, PLoS One 8 (9) (2013) e74489.

[15] H.A. Dierick, R.J. Greenspan, Serotonin and neuropeptide F have opposite modulatory effects on fly aggression, Nat. Genet. 39 (5) (2007) 678-682.

[16] O. Johnson, J. Becnel, C.D. Nichols, Serotonin 5-HT2 and 5-HT1A-like receptors differentially modulate aggressive behaviors in Drosophila melanogaster, Neuroscience 158 (2009) 1292-1300.

[17] E.A. Kravitz, Serotonin and aggression: insights gained from a lobster model system and speculations on the role of amine neurons in a complex behavior, J. Comp. Physiol. 186 (2000) 221-238.

[18] C.H. Summers, W.J. Korzan, J.L. Lukkes, M.J. Watt, G.L. Forster, O. Øverli, E. Höglund, E.T. Larson, P.J. Ronan, J.M. Matter, J.M. Summers, K.J. Renner, N. Greenberg, Does serotonin influence aggression? Comparing regional activity before and during social interaction, Physiol. Biochem. Zool. 78 (2005) 679-694.

[19] M.S. Livingstone, R.M. Harris-Warrick, E.A. Kravitz, Serotonin and octopamine produce opposite postures in lobsters, Science 208 (1980) 76-79.

[20] S. Pedetta, L. Kaczar, H. Maldonado, Individual aggressiveness in the crab Chasmagnathus: influences in fight outcome and modulation by serotonin and octopamine, Physiol. Behav. 101 (2010) 438-445.

[21] O.V. Alekeseyenko, C. Lee, E.A. Kravitz, Targeted manipulation of serotonergic neurotransmission affects the escalation of aggression in adult male Drosophila melanogaster, PloS One 10 (2010) 1371.

[22] G.S. Wilkinson, P.M. Johns, Sexual selection and the evolution of mating systems in flies, in: B.M. Wiegmann, D.K. Yeates (Eds.), The Evolutionary Biology of Flies, Columbia University Press, New York, 2005, pp. 312-329.

[23] I. De la Motte, D. Burkhardt, Portrait of an Asian stalk-eyed fly, Naturwiss 70 (1983) 451

[24] T. Panhuis, G.S. Wilkinson, Exaggerated male eye span influences contest outcome in stalk-eyed flies (Diopsidae), Behav. Ecol. Sociobiol. 46 (1999) 221-227.

[25] D. Burkhardt, I. de la Motte, Selective pressures, variability, and sexual dimorphism in stalk-eyed flies (Diopsidae), Naturwiss 72 (1985) 204-206. 
[26] D. Burkhardt, I. de la Motte, Physiological, behavioural, and morphometric data elucidate the evolutive significance of stalked eyes in Diopsidae (Diptera), Entomol. Gener. 12 (1987) 221-233.

[27] J. Small, S. Cotton, K. Fowler, A. Pomiankowski, Male eyespan and resource ownership affect contest outcome in the stalk-eyed fly, Teleopsis dalmanni, Anim. Behav. 78 (2009) 1213-1220.

[28] D. Burkhardt, I. de la Motte, Big 'antlers' are favoured: female choice in stalk-eyed flies (Diptera, Insecta), field collected harems and laboratory experiments, J. Comp. Physiol. A 162 (1988) 649-652.

[29] S. Cotton, J. Small, R. Hashim, A. Pomiankowski, Eyespan reflects reproductive quality in wild stalk-eyed flies, Evol. Ecol. 24 (1) (2010) 83-95.

[30] A.R. Egge, J.G. Swallow, Previous experience matters in the stalk-eyed fly Teleopsis dalmanni, Behav. Ecol. Sociobiol. 65 (2011) 1731-1737.

[31] Y. Brandt, Do the elongated eye stalks of diopsid flies facilitate rival assessment? Behav. Ecol. Sociobiol. 63 (2009) 1243-1246.

[32] A.R. Egge, Y. Brandt, J.G. Swallow, Sequential analysis of aggressive interactions in the stalk-eyed fly Teleopsis dalmanni, Behav. Ecol. Sociobiol. 65 (2) (2011) 369-379.

[33] A.N. Bubak, J.G. Swallow, K.J. Renner, Whole brain monoamine detection and manipulation in a stalk-eyed fly, J. Neurosci. Methods 219 (2013) 124-130.

[34] A.N. Bubak, K.J. Renner, J.G. Swallow, Heightened serotonin influences contest outcome and enhances expression of high-intensity behaviors, Behav. Brain Res. 259 (2014) 137-142.

[35] G.S. Wilkinson, Artificial sexual selection alters allometry in the stalk-eyed fly Cyrtodiopsis dalmanni (Diptera: Diopsidae), Genet. Res. Cambridge 62 (1993) 213-222.

[36] G. Ribak, A.R. Egge, J.G. Swallow, Saccadic head rotations during walking in the stalk-eyed fly (Cyrtodiopsis dalmanni), Proc. R. Soc. B 276 (2009) 1643-1649.

[37] D. Burkhardt, I. de la Motte, How stalk-eyed flies eye stalk-eyed flies: observations and measurements of the eye of Cyrtodiopsis whitei (Diopsidae, Diptera), J. Comp. Physiol. 151 (1983) 407-421.
[38] M.M. Bradford, A rapid and sensitive method for the quantitation of microgramquantities of protein utilizing the principle of protein-dye binding, Anal. Biochem. 72 (1976) 248-254.

[39] D.T. Blumstein, J.C. Daniel, C.S. Evans, Jwatcher Software. Available at http:// www.jwatcher.ucla.edu/, 2007.

[40] P.A. Stevenson, H.A. Hofmann, K. Schoch, K. Schildberger, The fight and flight responses of crickets depleted of biogenic amines, J. Neurobiol. 43 (2) (2000) 107-120.

[41] A. Baier, B. Wittek, B. Brembs, Drosophila as a new model organism for the neurobiology of aggression? J. Exp. Biol. 205 (9) (2002) 1233-1240.

[42] A.N. Bubak, J.L. Grace, M.J. Watt, K.J. Renner, J.G. Swallow, Neurochemistry as a bridge between morphology and behavior: perspectives on aggression in insects, Curr. Zool. 60 (6) (2014) 778-790.

[43] S.A. Adamo, C.E. Linn, R.R. Hoy, The role of neurohormonal octopamine during 'fight or flight' behaviour in the field cricket Gryllus bimaculatus, J. Exp. Biol. 198 (8) (1995) 1691-1700.

[44] S.C. Hoyer, A. Eckart, A. Herrel, T. Zars, S.A. Fischer, S.L. Hardie, M. Heisenberg, Octopamine in male aggression of Drosophila, Curr. Biol. 18 (3) (2008) 159-167.

[45] C. Zhou, Y. Rao, Y.A. Rao, Subset of octopaminergic neurons are important for Drosophila aggression, Nat. Neurosci. 11 (9) (2008) 1059-1067.

[46] J. Rillich, P.A. Stevenson, Winning fights induces hyperaggression via the action of the biogenic amine octopamine in crickets, PLoS One 6 (12) (2011) e28891.

[47] J. Rillich, P.A. Stevenson, Releasing stimuli and aggression in crickets: octopamine promotes escalation and maintenance but not initiation, Front. Behav. Neurosci. 9 (2015). 